\title{
Fazang's Total Power Mereology: An Interpretive Analytic Reconstruction
}

Nicholaos Jones

University of Alabama in Huntsville

nick[dot]jones[AT]uah[dot]edu

Author Posting. (c) Asian Philosophy, 2009.

This is the author's version of the work. It is posted here by permission of Asian Philosophy for personal use, not for redistribution.

The definitive version was published in Asian Philosophy, Volume 19 Issue 3, November 2009. doi:10.1080/09552360903230739 (http://dx.doi.org/10.1080/09552360903230739)

This is a penultimate draft. Please cite only the published version.

\begin{abstract}
In his Treatise on the Golden Lion, Fazang says that wholes are in each of their parts and that each part of a whole is every other part of the whole. In this paper, I offer an interpretation of these remarks according to which they are not obviously false, and I use this interpretation in order to rigorously reconstruct Fazang's arguments for his claims. On the interpretation I favor, Fazang means that the presence of a whole's part suffices for the presence of the whole and that the presence of any such part is both necessary and sufficient for the presence of any other part. I also argue that this interpretation is more plausible than its extant competitors.
\end{abstract}




\section{Fazang's Total Power Mereology: An Interpretive Analytic Reconstruction}

\section{The Realm of Indra's Net and Mutual Identification}

According to the seventh mystery of Fazang's Treatise on the Golden Lion, the "gate of the realm of Indra's net,"

In each of the lion's eyes, ears, limbs, joints, and in each and every hair, there is the golden lion. All the lions embraced by the single hairs simultaneously and instantaneously enter into a single hair. Thus in each and every hair there are an infinite number of lions, and in addition all the single hairs, together with their infinite number

of lions, in turn enter into a single hair. In this way the geometric progression is infinite, like the jewels of Celestial Lord Indra's net (as translated in Chan 1963, p.412).

Fazang's claim, that each part of the lion contains the lion itself, is not obviously true. Indeed, since parts do not contain the whole of which they are parts, in virtue of being contained in that whole, Fazang's claim seems to be false. For instance, part of what makes a lion's hair a part of the lion is that the lion is not in the hair: this is a consequence of the parthood relation being antisymmetric. So Fazang's claim seems to get the mereological relation between part and whole backwards, because a part is in its whole rather than the other way around.

This is not the only surprising claim that Fazang makes about mereology. Nor is it the most puzzling. In the fourth mystery of the same Treatise, the "gate of the mutual identification of dharmas existing freely and easily," he says

Since the various organs and each and every hair of the lion completely take in the lion by means of the gold, each and every one of them penetrates the whole. The eye of the lion is its ear, its ear is its nose, its nose is its tongue, and its tongue is its body. They 
each exist freely and easily, one not hindering or obstructing the other (as translated in Chan 1963, p.411).

Fazang here asserts that the various parts of the lion are each other. If he means that each part is numerically identical to the others, the fourth mystery helps to explain the seventh. For if the lion has one part, albeit a part called by different names, presumably that part is coextensive with the lion as a whole (lest, per impossible, the lion have exactly one part and, in addition, some other part). Since there seems to be a sense in which coextensive objects contain each other-such as the sense in which Mr. Hyde and Dr. Jekyll are in each other--it follows that the lion is in the lion's part. Yet if Fazang means that the lion's parts are numerically identical to each other, his claim seems to be false, since the lion seems to have more than one part.

There is some reason to suppose that Fazang does not mean to say, literally, that each whole has exactly one part and is in this part. For instance, in the eighth section of the Treatise, Fazang claims that the five sense organs of the lion are "various and different." So, in saying that the lion's eye is its ear, Fazang probably does not mean that the lion's eye is numerically identical to its ear. Moreover, Fazang claims that the way in which the lion is in its parts resembles the way in which Indra's net is in each of the net's jewels. If, as it seems, the net as a whole is not in a jewel as part of the jewel's structure, but rather in a jewel merely as a reflection or cause of the jewel's properties, then Fazang also does not mean that wholes are actually in their parts. (Further reasons against a literal interpretation of Fazang's remarks occur below.)

Of course, an idea about what Fazang's mereological claims do not mean does not, by itself, determine what his claims do mean. A satisfactory interpretation of Fazang's claims should provide a sense of identity according to which numerically distinct entities can be 
identical to each other. If possible, the interpretation also should not invoke violations of the principle of noncontradiction. For an interpretation that does this is, ceteris paribus, better than one that does not.

This paper adopts an interpretation of Fazang's remarks according to which his claim that a whole is in one of its parts means that the presence of the whole is a necessary condition for the presence of the part (or, equivalently, that the presence of any one part suffices for the presence of the whole), and according to which his claim that one part of a whole is another of the whole's parts means that the presence of the one part is both necessary and sufficient for the presence of that other part. This interpretation permits construing Fazang's reasoning about mereology in his Treatise on the Five Teachings of Huayan as valid arguments rather than gross nonsequitirs. (Section 4 contains further evidence for these interpretive assumptions.)

The remainder of this paper discusses Fazang's arguments for the theses that wholes are in their parts and each part of a whole is every other part of the whole. Section 2 shows that the first thesis is equivalent to Fazang's assertion, in Treatise on the Five Teachings of Huayan, that parts have total, rather than only partial, power to create wholes; and it reconstructs Fazang's argument for this assertion. Section 3 shows that the second thesis is a corollary to Fazang's claim that every part of a whole has the characteristic of universality; and it reconstructs Fazang's argument for why parts have this characteristic. Section 4 considers alternative ways to interpret Fazang's claims about wholes being in their parts and parts being identical to each other; and it shows that none of these competitors cohere with Fazang's philosophy as well as the interpretation that this paper advocates.

This discussion of Fazang's mereology differs from others in being more analytic than exegetic. For instance, Francis Cook characterizes Fazang's discussion of the six characteristics 
as so "clear and informative" that it "does not really need much commentary" (Cook 1977, p.76). Accordingly, Cook's method in discussing Fazang's arguments is to repeat them and add examples where appropriate. (See below for an example of this.) In contrast, this paper's method in discussing Fazang's arguments is to add missing premises and explain inferential transitions, in order to make explicit the logical structure of Fazang's reasoning and its hidden presuppositions. The goal of this paper is to understand not only what Fazang's claims mean but also why Fazang might endorse those claims.

\section{Total Power Parts}

When a strong wind causes a building to collapse into a heap, the elements of the heap seem to be rafters, planks, tiles, and so on. The only apparent difference between the building and the heap is the arrangement of the building parts. If these appearances are correct-if the building and the heap differ structurally but not compositionally - then the mere presence of a building part does not suffice for the building's presence and the building's parts have what Fazang calls only partial power to create the building: "if each part does not wholly cause the building to be made and only exerts partial power, then each condition [such as the rafter] would have only partial power." (This and subsequent quotations from Fazang's Treatise on the Five Teachings of Huayan come from the translation in Cook 1977, pp.76-89.) If, however, the appearances are incorrect, so that the elements of the heap are not building parts despite undergoing no apparent intrinsic change, then the building's presence is necessary to each building part's presence. This latter possibility entails that the presence of a building part suffices for the presence of the building, which is to say, in Fazang's language, that each building part has total power to create the building. If a whole being in one of its parts means that the presence of the 
part suffices for the presence of the whole, wholes are in their parts just if parts have total power to create wholes. ${ }^{1}$

Fazang argues that parts do not have only partial power to create their wholes. He infers that, appearances to the contrary, parts have total power to create their wholes, presumably because this is the lone alternative to their having only partial power.

[I]f the rafter does not wholly create the building, then when the one rafter is removed, the whole building should remain. However, since the total building is not formed, you should understand that the building is not formed by the partial power of a condition such as the rafter but by its total power (Treatise on the Five Teachings of Huayan). Francis Cook offers the following commentary:

if the rafter does not have this total power, then if the rafter is removed, the whole building should remain, just as my whole body should remain if a leg is amputated. Obviously this is not the case, and so [Fazang] says that in order for the whole to be a whole, the part must exert total power in the formation of the whole $(1977, \mathrm{p} .81)$. Cook's explication highlights the two key premises of Fazang's argument: first, that parts are not necessary conditions for their wholes if the parts have only partial power; second, that parts are necessary conditions for their wholes.

Cook's commentary nicely illustrates these premises. However, it does not explain why Fazang might endorse them. Cook rephrases the first and illustrates what the relation between a body and a leg would be if that claim were true. But any doubts about Fazang's claim simply transfer to doubts about Cook's illustration. He accepts Fazang's second premise as self-evident, ignoring the intuition that buildings apparently can survive, say, broken windows and fallen shingles. 
Fazang, fortunately, hints at a justification for the second premise-that the absence of a part entails the absence of its whole-when he answers the question, "why would there be no building if a single rafter is lacking?" According to Fazang, a building without a rafter is a "spoiled building, not a perfect building." Cook explicates this as the claim that "when a part is removed, the previously perfect whole is destroyed; it just is not that particular whole anymore" (1977, p.82). This seems to indicate that Fazang adopts a strict and exacting identity condition for wholes, known among contemporary metaphysicians as Mereological Essentialism, according to which wholes cannot survive any loss or replacement of their parts. (See, for example, Chisholm 1973.) Insofar as he does, he also might accept the contemporary defense of Mereological Essentialism against the intuition that a building can survive the loss of a window: although what remains is (nearly) functionally identical to the original building, it is ontologically distinct from the original building, the same as the original building in a loose and popular sense but not the same in a strict and philosophical sense.

Fazang does not indicate a justification for the premise that parts are not necessary conditions for their wholes if the parts have only partial power. This is unfortunate, because considerations of intuitive plausibility favor rejecting this premise as false rather than accepting as true the conclusion it supports. Moreover, the premise is not a logical truism: that a whole is not necessary to its parts does not entail that those parts are not necessary to their whole. For example, a rafter's presence can be insufficient for a building's presence (in virtue of the rafter being part of a mere heap), but this is compatible with the building's presence requiring the rafter's. This all suggests that Fazang's justification for this premise must rely upon a substantial metaphysical assumption. 
To the best of my knowledge, Fazang nowhere indicates what this assumption might be. Two pieces of circumstantial evidence, however, provide a clue. The first is that, when possible, the Huayan school prefers symmetry and inclusiveness to asymmetry and exclusivity: according to Huayan, no event is more causally basic than any other (Cook 1979), all times-past, present, future-are equally real and equally causally efficacious (Vorenkamp 2005), and so on. The second is that the premise in question concerns a relation between a whole and its parts. This evidence defeasibly suggests that Fazang's unstated justification is the assumption that the relation between wholes and their parts is, in some (non-technical) sense, symmetric, so that wholes bear to their parts the same relations as parts bear to their wholes. I shall call this assumption Naïve Part-Whole Symmetry.

Naïve Part-Whole Symmetry entails that if wholes are not necessary to their parts, parts are not necessary to their wholes. This provides a potential justification for Fazang's claim that "if the rafter does not wholly create the building, then when the one rafter is removed, the whole building should remain." For a part does not have total power to create its whole just if the whole is not necessary to the part, and a whole survives removal of one of its parts just if those parts are not necessary to the whole. Despite this, Naïve Part-Whole Symmetry is obviously false. Consider, for example, the smaller than relation. Some parts are smaller than their wholes; but these wholes are not smaller than those parts. So attributing Naïve PartWhole Symmetry to Fazang violates the principle of charity, which demands that one not ascribe obviously false assumptions to others without undue cause.

Nonetheless, Naïve Part-Whole Symmetry is almost correct. The relation at issue with the premise in question is that of being unnecessary to. This differs from those relations, such as being smaller than, that generate counterexamples to Nä̈ve Part-Whole Symmetry. For, 
among other differences, the counterexample-generators are irreflexive: they are relations that entities never bear to themselves. (For instance, nothing is smaller than itself.) This suggests qualifying Naïve Part-Whole Symmetry:

Qualified Part-Whole Symmetry: Wholes bear the same non-irreflexive relations to their parts as parts bear to their wholes.

Qualified Part-Whole Symmetry entails that if wholes are not necessary to their parts, parts are not necessary to their wholes, since the relation being unnecessary to is non-irreflexive: some (indeed, all) entities are such that their presence is necessary to their presence. (A nonirreflexive relation is one that entities sometimes, but not necessarily always, bear to themselves.) It also avoids the counterexamples to Naïve Part-Whole Symmetry. Accordingly, Qualified Part-Whole Symmetry offers a potential justification of Fazang's claim, it respects the Huayan affinity for symmetry, and attributing this assumption to Fazang does not violate the principle of charity.

If Qualified Part-Whole Symmetry is true, parts are not necessary to their wholes if they have only partial power to create those wholes (that is, if wholes are not necessary to their parts). If Mereological Essentialism is true, parts are necessary to their wholes. Accordingly, these assumptions entail that parts have total, rather than only partial, power to create their wholes. For the sake of brevity, I shall refer to this conclusion as the thesis of Total Power Parts.

Total Power Parts entails that wholes are in each of their parts. This explains why Fazang claims, in his Treatise on the Golden Lion, that the lion is in each of the lion's organs, limbs, joints, and hairs. Each of these lion parts has total, rather than only partial, power to create the lion. Since the presence of a part is a sufficient condition for the presence of its whole if the part has total power to create the whole, the presence of any of the lion's parts 
suffices for the presence of the lion. Given the interpretive assumption that a whole is in one of its parts just if the presence of that part suffices for the presence of the whole, it follows that the lion is in each of its organs, limbs, joints, and hairs.

This preceding discussion of Fazang's argument for Total Power Parts differs from Cook's. Cook mentions no supplemental assumptions like Mereological Essentialism and PartWhole Symmetry. Instead, he offers examples to illustrate Fazang's premises. This fits with the purpose of his discussion, which is to provide an illustrative reconstruction of Fazang's argument. The purpose here, however, is to offer an analytic reconstruction of Fazang's argument - a reconstruction that explains why Fazang might endorse his argument's premises rather than one that illustrates what those premises mean. The role of Mereological Essentialism and Part-Whole Symmetry, accordingly, is to make explicit that Fazang's counterintuitive premises follow from more general principles that are not obviously false (or that are at least defensible as not false).

\section{Universality and Mutual Identity}

Total Power Parts, by itself, does not explain why Fazang claims that each lion part is every other lion part. Even if two entities individually suffice for a third, it does not follow that those two entities are identical to each other. Nor does it follow that they are either necessary or sufficient for each other's presence. (For example, consider four quarters and ten dimes, both of which suffice for buying a bottle of soda.) Accordingly, understanding why Fazang claims that each lion part is every other lion part requires supplementing Total Power Parts with some additional assumptions. This section states those further assumptions, shows how the resultant set of assumptions entails Fazang's claim that every part of a whole has the characteristic of 
universality, and demonstrates that Fazang's claim about the mutual identity of lion parts follows from those parts having that characteristic.

There are two assumptions that, in conjunction with Total Power Parts, entail that the parts of a whole are mutually identical to each other. The first is Mereological Essentialism, namely, that each part of a whole is necessary to the whole. This is a view that Fazang seems to presuppose in arguing for the thesis that parts have total power to create their wholes. The second assumption, which I shall call Chinese Buddhist Identity, is that one entity is another entity just if the presence of the one is both necessary and sufficient for the presence of the other. This assumption accords with Rein Raud's analysis of the identity relation in Chinese Buddhism, according to which numerically distinct things are identical "when if one is absent, the other is absent too" (2003, p.140).

Mereological Essentialism and Total Power Parts jointly entail that each part of a whole is both necessary and sufficient for that whole. Hence, given Chinese Buddhist Identity, it follows that each part of a whole is that whole. This argument is based upon one that Fazang gives, in his Treatise on the Five Teachings of Huayan, when explaining what it means to say that dharmas have the characteristic of universality [zong].

Question: what is the universal? Answer: it is the building. Question: that is nothing but various conditions, such as a rafter; what is the building itself? Answer: the rafter is the building. Why? Because the rafter by itself totally makes the building. If you get rid of the rafter, the building is not formed. When there is a rafter, there is a building. Analogizing dharmas to building parts, Fazang's idea seems to be that each dharma/building part has a characteristic, called universality, which consists in its being (in some sense) its whole. So, for example, a rafter's universality consists in its being (in some sense) its building. Fazang 
explains that a rafter is its building for two reasons: first, because the rafter 's presence is a sufficient condition for the building's presence; second, because the rafter's presence is a necessary condition for the building's presence. The first of these expresses Total Power Parts; the second, Mereological Essentialism. Chinese Buddhist Identity secures the inference to the claim that the rafter is the building. I shall call the more general version of this claim, according to which each part of a whole is that whole, Universality.

Universality entails that each part of a whole is every other part of that whole, in the sense of "is" that Chinese Buddhist Identity captures. Consider, say, a rafter and a plank from a common building. The rafter and the plank both have universality: each is the building, in the sense that each is both necessary and sufficient for the building. So the rafter's presence suffices for the plank's presence, because the rafter suffices for the building and the building suffices for the plank. The rafter's presence also is necessary to the plank's presence, because there is no building if there is no rafter and there is no plank if there is no building. Hence, the rafter is the plank, in the sense of "is" that Chinese Buddhist Identity captures. Since similar arguments hold for any two parts of the building, each building part is every other building part: the building parts are mutually identical.

The mutual identity among a whole's parts explains why, in his Treatise on the Golden Lion, Fazang claims that "The eye of the lion is its ear, its ear is its nose, its nose is its tongue, and its tongue is its body." Each of the lion's parts has the characteristic of universality. That is, for any given lion part, the presence of that part is both necessary and sufficient for the presence of the lion. This entails that the presence of the lion's eye is both necessary and sufficient for the presence of its ear, that the presence of the lion's ear is both necessary and sufficient for the presence of its nose, that the presence of the lion's nose is both necessary and 
sufficient for the presence of its tongue, and that the presence of the lion's tongue is both necessary and sufficient for the presence of its body. Given the interpretive assumption of Chinese Buddhist identity, it follows that each of these lion parts is every other lion part.

\section{Competing Interpretations}

Thus far, I have defended two theses: first, that Fazang's claim about wholes being in their parts follows from his claim that parts have total power to create their wholes; secondly, that his claim about each part of a whole being every other part of the whole follows from his claims that parts are necessary conditions for their wholes and that parts have total power to create their wholes. The arguments in favor of these theses depend upon two interpretative theses: first, that Fazang's claims about wholes being in their parts are claims about wholes being necessary conditions for their parts; secondly, that Fazang's claims about one part of a whole being some other part of the whole are claims about the one part's presence being both necessary and sufficient for the other part's presence. I am referring to the latter interpretive thesis as Chinese Buddhist Identity. For the sake of brevity, I shall refer to the former as Inherence Is Necessity.

There is circumstantial evidence for each interpretive thesis. For instance, in his Treatise on the Five Teachings of Huayan, Fazang characterizes the view that the presence of one rafter suffices for the presence of a building-or, equivalently, that the building's presence is necessary for the rafter's-as the view that "the perfect building is inherent in the one rafter." This supports Inherence Is Necessity. (See Chang (1971, pp.122-125) for a similar interpretation.) Regarding Chinese Buddhist Identity, Rein Raud argues that, in the context of Chinese Buddhism, distinct things are identical "when if one is absent, the other is absent too" 
(2003, p.140; also see Jones 2010). If, for any two parts of a whole, either part's absence suffices for the other's absence, the presence of either part suffices for the presence of the other. Hence, if Raud's analysis is correct, two parts of a whole are identical just if one's presence is necessary and sufficient for the other's.

This evidence is not decisive. There are competing, prima-facie plausible ways to interpret Fazang's claims. These alternative interpretations constitute a challenge to the theses defended in previous sections because, if the alternatives are correct, the arguments in those sections are unsound. Accordingly, in this section, I shall argue that several competing interpretive theses are less plausible than the ones I invoke. The basis for my claims about plausibility shall be the extent to which the various interpretive theses cohere with Fazang's philosophy.

Consider, first, an alternative to Inherence Is Necessity, according to which Fazang's claim about a lion being in its hair means that the essence of the lion, rather than the lion itself, is in its hair. For example, according to this interpretation, if a lion's essence consists in its genetic code, then the lion is in each of its eyes, ears, limbs, joints, and so on just if each of these parts contain the lion's genetic code. ${ }^{2}$ This interpretation does not require foisting upon Fazang a (non-Buddhist) commitment to wholes having unchanging essences, since essences like genetic codes can be mutable and relatively transient. However, if this interpretation is correct, Fazang's claim about wholes being in their parts does not follow from his claim that parts have total power to create their wholes, since parts having such power does not guarantee that each part contains the essence of its whole.

Inherence Is Necessity is superior to this essentialist interpretation, in virtue of better accommodating Fazang's claim that "in each and every hair there are an infinite number of lions, 
and in addition all the single hairs, together with their infinite number of lions, in turn enter into a single hair." If this claim is not to be interpreted as patently false, its reference to an "infinite number of lions" must not be literal. There is one lion, and only this lion is in the lion's hair. Fazang's idea seems to be that, within the lion that is in the lion's hair, there is that lion's hair; and within this hair in the lion that is in the hair, there is the lion; and so on ad infinitum. Accordingly, the charitable reading of Fazang's reference to an "infinite number of lions" is that there is a never-ending regress of the lion being in the lion's hair and that very same hair being in the very same lion: neither the lion nor the lion's hair is more fundamental than the other, in terms of one being in the other. (For a similar interpretation of this remark, see Jones 2010.) Consider, then, an essentialist interpretation of Fazang's claim. It says that the lion's hair contains the lion's essence, which in turn contains the lion's hair, which in turn contains the lion's essence, and so on ad infinitum. Yet the basic idea of a lion's essence is that it is, at the very least, something that does not have all of the lion's properties. The lion's genetic code, for instance, does not have hair or eyes or ears-it has only the blueprints for these lion parts. Hence, the essentialist reading makes implausible Fazang's claim that what it is that is in the lion's hair also contains the lion's hair. For instance, according to the essentialist interpretation, if the lion's essence is its genetic code, the lion's essence is in the lion's hair but the lion's hair is not in its genetic code. At best, a code for the lion's hair is in the lion's genetic code. This code for the lion's hair, however, is a proper subset of the lion's genetic code. So the lion's genetic code is not in the code for the lion's hair, and there is not an ever-lasting regress of the lion's essence being in the lion's hair and that very same hair being in that very same essence, contrary to Fazang's claim. 
Inherence Is Necessity better accommodates Fazang's remark. This interpretation says that the lion's presence is a necessary condition for the presence of the lion's hair. Given Mereological Essentialism, the presence of the lion's hair also is a necessary condition for the lion's presence. So the lion and its hair are necessary to each other. This is consistent with neither the lion nor its hair having ontological priority: mutual necessity does not demand that, say, the lion's hair be more fundamental than the lion. This is also consistent with there being a never-ending regress of the lion being in the lion's hair, which is in the lion, which is in the lion's hair. For there is a never-ending regress of the lion being a necessary condition for the lion's hair, which is a necessary condition for the lion, which is a necessary condition for the lion's hair. Hence, compared to the essentialist interpretation, Inherence Is Necessity is a better interpretation of Fazang's claims about wholes being in their parts.

There are, to the best of my knowledge, two extant competitors to Chinese Buddhist Identity. The least plausible is due to Garma Chang, according to whom Fazang means that each part of a whole is numerically identical to every other part of the whole when he says that each part of a whole is every other part (1971, pp. 121-122, 132-139). Chang's interpretation fits poorly with other remarks that Fazang makes. For instance, in the Treatise on the Golden Lion, Fazang claims that "All phenomena are in great profusion, and are interfused but not mixed (losing their own identity)." This entails that there are at least two things. Yet if all phenomena are mutually identical, in virtue of being parts of the same totality, and if mutual identity is numerical identity, there is only one thing.

Chang's interpretation also fails to accommodate Fazang's discussion of the first and fourth characteristics of dharmas, universality and difference [yi]. In the Treatise on the Five 
Teachings, Fazang clarifies that Universality is not a claim about each whole's part being numerically identical to its whole.

Question: if the whole is identical with the parts, how can it be a whole? Answer: it can be a whole precisely because it is identical with the parts. Just as the rafter is identical with the building, which is called the characteristic of universality, so also because it is a rafter, we speak of the characteristic of particularity.

Here Fazang states that, although the rafter is identical with its building, it remains a rafter rather than, say, a plank. This further supports not construing Fazang's claims about identity as claims about numerical identity. For if a part's universality were to consist in its being numerically identical to its whole, a building's rafter would be exactly the same as the building's planks, tiles, and so on. However, if Chinese Buddhist Identity provides a correct interpretation of Fazang's claims about identity, a building part being identical with its building allows that part to remain numerically distinct from other parts of the building.

Similarly, Chang's interpretation fails to accommodate Fazang's discussion of the fourth characteristic of dharmas, difference. As it pertains to building parts, Fazang describes this characteristic as the fact that "all the conditions [parts of the building], such as the rafter, are distinct within the one building." Fazang clarifies that distinctness means numerical distinctness. For, he argues, if the building parts are not numerically distinct, then since the rafter is eleven feet long, the tiles would be the same, and since this would destroy the original condition [that is, the presence of multiple building parts] ... they could not function identically as conditions for the building.

That is, if a building's parts are numerically identical, all of the parts would be the same; and if all of the parts are the same, those parts cannot form a whole building. Since, however, there is 
a building (at least according to Fazang), this building's parts are numerically distinct from each other. If Chang's interpretation is correct, Fazang is mistaken or confused (or willfully abandoning the principle of noncontradiction) in claiming that buildings have multiple proper parts. Chinese Buddhist Identity, in contrast, readily accommodates Fazang's remarks concerning the characteristic of difference. For the building's parts being necessary and sufficient for each other is consistent with those parts being numerically distinct.

Francis Cook offers a more plausible competitor to Chinese Buddhist Identity, according to which Fazang, when he says that each part of a whole is every other part, means that each part of a whole is, in virtue of being empty, similar to every other part of the whole. For example, according to Cook's interpretation, "The emperor of China and a sand flea are ... identical in the sense that they are both empty, both interdependent, both conditions for the totality of existence" (1977, p.85). (For a similar interpretation, see Odin 1982, p.20.)

Chinese Buddhist Identity is superior to Cook's interpretation, because it better captures Fazang's rationale in treating Huayan Buddhism as superior to Tiantai Buddhism. In one of his better known classification schemes, Fazang ranks Buddhist teachings as correct to the degree that each attains the ideal of the round, according to which a teaching embodies ultimate truth insofar as it is all-inclusive and free from extremes. Fazang uses this ranking criterion to establish that Huayan Buddhism is more correct than Tiantai. For, according to Fazang, whereas both Huayan and Tiantai mereology hold that each part of a whole is identical to that whole, only Huayan mereology adds that each part of a whole is identical to every other part of that whole. (For further discussion, see Jones forthcoming and Liu 1981.) Cook's interpretation of Fazang's identity claims cannot capture this difference. 
According to Cook, the thesis that the parts of a whole are mutually identical means that each part of a whole is similar to every other part of that whole in virtue of being empty. According to Chinese Buddhist Identity, the thesis means that each part of a whole is necessary and sufficient for any other part of that whole. Tiantai Buddhists accept that the parts of a whole are similar in virtue of being empty, because all Buddhists accept that whatever exists is empty. Yet, according to Fazang, they deny that the parts of a whole are mutually identical. Hence, if Cook's interpretation is correct, either there is no difference between Huayan and Tiantai mereology, in which case Fazang is mistaken in taking Huayan Buddhism to attain the ideal of the round better than Tiantai, or else Huayan and Tiantai Buddhists have different concepts of identity, in which case equivocation with respect to identity claims vitiates Fazang's ranking scheme. In contrast, Chinese Buddhist Identity requires attributing to Fazang neither of these errors: according to this interpretation, Huayan and Tiantai disagree over whether each part of a whole is necessary and sufficient for every other part of that whole.

\section{Conclusion}

Fazang's Treatise on the Golden Lion contains two provocative mereological claims, namely, that parts of a whole contain their whole and are identical to each other. If interpreted literally, these claims are obviously false, because wholes contain without being contained and exist as wholes in virtue of having multiple parts. The task of this paper, accordingly, has been to offer an alternative interpretation, according to which Fazang means that the presence of a whole's part suffices for the presence of the whole and that the presence of any such part is both necessary and sufficient for the presence of any other part. This interpretation has three virtues. First, it respects the principle of charity in virtue of allowing us to understand Fazang's 
claims in a way that is not obviously false. Secondly, it supports a reconstruction of the arguments Fazang uses to establish his claims and thereby helps us to understand why Fazang might endorse them. Finally, in comparison with competing interpretations, it better coheres with the rest of Fazang's philosophy.

\section{Acknowledgements}

I thank Adam Podlaskowski, Bill Wilkerson, and Thomas Watts for helpful discussion and comments on earlier versions of this paper.

\section{References}

Chan, Wing-Tsit. (1963). A source book in Chinese philosophy. Princeton: Princeton University Press.

Chang, Garma C.C. (1971). The Buddhist teaching of totality: The philosophy of Hwa-yen Buddhism. University Park, PA: The Pennsylvania State University Press.

Chisholm, R. (1973). Parts as essential to their wholes. Review of Metaphysics, 26(4), 581-603.

Cook, F.H. (1977). Hua-Yen Buddhism: The jewel net of Indra. State College, PA: Penn State Press.

Cook, F.H. (1979). Causation in the Chinese Hua-Yen tradition. Journal of Chinese Philosophy, 6, 367-385.

Jones, N. (2010). Mereological heuristics for Huayan Buddhism. Philosophy East \& West, 60(3). Jones, N. (forthcoming). Fazang: Hermeneutics, causation, and mereology. In S.A. Wawrytko (Ed.), Dao companion to Chinese Buddhist philosophy. Springer. 
Liu, M-W. (1981). The p'an-chiao system of the Hua-yen school in Chinese Buddhism. T'oung Pao 67(1-2), 10-47.

Odin, S. (1982). Process metaphysics and Hua-yen Buddhism: A critical study of cumulative penetration vs. interpenetration. Albany: State University of New York Press.

Raud, R. (2003). The genesis of the logic of immediacy. Asian Philosophy, 13(2/3), 131-143.

Vorenkamp, D. (2005). Reconsidering the Whiteheadian critique of temporal symmetry in light of Fazang's views. Journal of Chinese Philosophy, 32(2), 197-210.

\section{Notes}

\footnotetext{
${ }^{1}$ Francis Cook offers a different interpretation of what Fazang means in saying that one
} thing has total power to create some other thing. According to Cook, a dharma has total power to create a result just if "the result is not able to be formed in the absence of the single dharma" (1977, p.67). That is, according to Cook, when Fazang claims that each part of a whole has total power to create that whole, he means that each part is a necessary condition for its whole. This interpretation does not fit Fazang's usage. Parts have total power to create their wholes just if they do not have only partial power to do so. Hence, if Cook is correct, saying that a part has only partial power to create its whole means that the part's presence is not necessary for its whole's presence. Yet, when Fazang says that a part has only partial power to create its whole, he means that the part's presence is not sufficient for the whole's presence.

Elsewhere, Cook remarks that

To possess total power means [to possess] the causative power of the whole building. Partial power, on the other hand, is simply the power in the rafter itself. What this 
really means, presumably, is that if the rafter were to exert only the causative power of itself--i.e., to exert the power of its rafterness--then it could never truly become integrated into the total building and become the building. In this case, no building would be possible. However, once integrated into the whole building, the rafter assumes the causative power of the whole building and thus acts as total cause for it (1977, p.81).

This is confused. If the rafter obtains its total power only after being integrated into the building, the building's existence precedes the rafter's having total power, and so the rafter cannot be a cause of the building, since the building already exists.

${ }^{2}$ I thank Thomas Watts for this suggestion. 